\title{
I \\ DE VICENTE A FLORESTAN: A TRAJETÓRIA DE UM DOS PRINCIPAIS PENSADORES DO BRASIL ${ }^{*}$
}

Paulo Honorato

\section{INTRODUÇÃO}

A memória é um dos artefatos mais importantes da consciência humana. Lembrar é tornar vivo, tornar vivo é manter forte a chama revolucionária de intelectuais militantes que deram a vida pelos seus ideais, como Florestan Fernandes.

Florestan Fernandes foi um dos intelectuais mais leais a sua classe de origem e tinha plena convicção da dificuldade que seria se manter fiel aos seus princípios, estando ele inserido em uma sociabilidade capitalista, nas palavras do próprio autor "[...] a coisa mais difícil que fiz foi permanecer fiel à minha classe de origem" (FERNANDES, 1991, p. 01). Reconhecer-se enquanto pertencente à classe trabalhadora, enfrentando a sociabilidade capitalista que captura cotidianamente a subjetividade dos trabalhadores é uma tarefa que exige rigor e análise crítica da realidade e, principalmente, lealdade para com seu "lugar de origem".

Reconhecido como um dos maiores sociólogos brasileiros, seu prestígio ultrapassou as barreiras geográficas, tendo adquirido destaque e respeito também fora do país. Em seu currículo consta o título de primeiro estrangeiro a ser professor titular na Universidade de Toronto (tendo recebido tal convite quando foi exilado pela ditadura empresarial-militar brasileira), porém, mesmo tendo alcançado os mais elevados postos de prestígio dentro e fora das universidades brasileiras e internacionais, jamais deixou de ter como horizonte intelectual militante a sua origem de classe, lutando até o fim pela defesa de um projeto de sociabilidade que atendesse às demandas e lutas dos "de baixo".

Para isso, Fernandes buscou entender a ordem burguesa, elaborando uma contribuição à teoria do desenvolvimento capitalista e ao exame da inser-

*DOI- 10.29388/978-65-86678-36-9-0-f.25-40 
ção capitalista dependente da América Latina e, particularmente do Brasil, na ordem mundial.

Para além de se realizar um relato biográfico, a preocupação do presente capítulo é apresentar ao leitor elementos que possibilitem entender o que influenciou a trajetória pessoal e acadêmica do autor para que ele se tornasse o grande intelectual militante que se tornou, especialmente, na elaboração de uma teoria social que explica as particularidades do desenvolvimento do capitalismo no Brasil, destacando, sobretudo, a construção de um de seus principais conceitos, capitalismo dependente, o que o elevou a condição de um dos maiores pensadores da realidade brasileira.

Quando se lê qualquer texto que seja de autoria de Florestan Fernandes, o leitor se vê diante de um autor completamente vivo, que fascina pelo seu viés crítico, rigor científico-analítico e seriedade nos debates que travava. Sendo assim, é assertivo apontar para o fato de que a obra do autor permanece atual, mesmo tendo passado 50 anos da elaboração de alguns de seus textos. Nesse sentido, Fernandes é fundamental para que se compreenda tanto os fatos históricos quanto a realidade atual.

Conhecido por ser um autor que fazia uma crítica veemente à contradição entre capital e trabalho, fez trabalhos monumentais nos quais o corte de classe é o eixo condutor, dialogando com a questão indígena; a questão racial (sendo um dos primeiros intelectuais a trazer o negro para o centro do debate, retirando-o do lugar de objeto de estudo para ser o sujeito pesquisador); a sociabilidade da criança, quando debateu sobre as "trocinhas de São Paulo"; a defesa da educação pública, gratuita, de qualidade e universal em todos os seu níveis, com o objetivo de romper com os padrões colonizadores do saber, acreditando que a "reforma universitária" estava indissociável da transformação social, na qual o socialismo era, e permanece sendo, o único horizonte possível de sociabilidade.

Apresentar alguns aspectos da trajetória pessoal e intelectual de Florestan Fernandes é, portanto, a tarefa que nos propomos realizar.

\section{DE VICENTE A FLORESTAN}

Analisar o pensamento intelectual militante de Florestan Fernandes é mais do que tratar de um pensador que contribuiu para construção da sociologia crítica no Brasil, de alguém que encarou de forma consciente os temas reais do seu tempo e se fez ferramenta de combate a favor dos "de baixo". Segundo 
o depoimento do seu companheiro, em uma amizade que perdurou a vida toda, Antônio Candido, Florestan Fernandes foi um homem que construiu a si mesmo em um movimento dialético constante de "[...] consciente aperfeiçoamento pessoal, sob todos os aspectos que caracterizaram a sua vida" (CÂNDIDO, 2001, p. 65).

Para o próprio Fernandes, $(1977$, p. 142) sua história de vida era o pano de fundo no qual se desenvolveu enquanto intelectual militante,

Eu jamais teria sido o sociólogo em que me converti sem o meu passado e sem a socialização pré e extraescolar que recebi, através das duras lições da vida. Para o bem e para o mal - sem invocar-se a questão do ressentimento, que a crítica conservadora lançou contra mim - minha formação acadêmica superpôs-se a uma formação humana que ela não conseguiu destorcer nem esterilizar.

Dessa forma, evocar a sua trajetória se faz necessário, para entendermos de onde ele saiu até onde ele chegou, inserindo-o na realidade do seu tempo, a fim de compreendermos como Fernandes fez das duras lições da vida, campo fértil para sua análise e militância.

Florestan Fernandes nasceu no dia 22 de julho de 1920, filho de Dona Maria Fernandes, uma migrante portuguesa, analfabeta e empregada doméstica, seu pai era desconhecido. Segundo relatos de estudiosos de sua vida e obra como Cerqueira (2013, p. 12), “[...] seu parto envolveu risco de vida por desnutrição".

Durante a gestação, Maria Fernandes trabalhava na casa de um casal da família Bresser, que ocupavam o alto escalão da classe média paulistana. Nesse período, fez amizade com o motorista da família, que dividia com ela seu alimento, preocupado com sua condição de gestante, pois, na casa dos patrões, a comida era regulada. Sendo assim, o amigo muitas vezes lhe dava sua refeição e comia na rua, para que ela pudesse se alimentar. Em gratidão ao gesto do motorista, Maria Fernandes decide batizar o filho pelo nome de Florestan, como uma forma de homenagear a generosidade e sensibilidade do amigo de trabalho que tantas vezes aliviou a dura realidade que vivia ${ }^{1}$.

Maria Fernandes convidou seus patrões para batizarem seu filho. Como o casal não tinha filhos, aceitou o convite com carinho, mas um carinho que se limitava a relação entre empregadores e empregados. Prova disso é o fato da madrinha (Hermínia Bresser de Lima) do recém-nascido não achar

${ }^{1}$ As informações contidas nesse parágrafo foram extraídas do documentário "Florestan Fernandes o mestre", uma produção da TV Câmara, 2013. 
apropriado que a criança recebesse o batismo de Florestan, pois o nome possuía muita "pompa" para o filho de uma simples empregada doméstica, sendo assim, decidiram chamar o garoto de Vicente. Maria Fernandes não contrariou os chefes, mas jamais deixou de chamar o filho por Florestan.

Florestan Fernandes viveu na casa dos padrinhos até os 05 (cinco) anos de idade. Fernandes (1980, p. 11-12) se recorda dessa fase com carinho, pois os padrinhos, embora não o chamassem pelo nome de batismo, por preconceito de classe, introduziram em sua vida o gosto pela leitura. Ele se recordava de que embora não estivesse tido uma educação regular, foi na casa da madrinha que aprendeu a estudar e com pouco mais de seis anos já adquirira disciplina pelos estudos.

Cabe destacar que o primeiro contato com a leitura foi decisivo para despertar uma paixão que o acompanhou por toda vida e, sempre que questionado sobre a educação formal, Fernandes destacava que o processo de educação de um sujeito social não está atrelado exclusivamente as instituições formais de ensino, pois,

[...] ainda que isso pareça pouco ortodoxo e anti-intelectualista, afirmo que iniciei a minha aprendizagem "sociológica" aos seis anos, quando precisei ganhar a vida como se fosse um adulto e penetrei, pelas vias da experiência concreta, no conhecimento do que é a convivência humana e a sociedade, em uma cidade na qual não prevalecia a 'ordem das bicadas', mas a 'relação de presa', pela qual o homem se alimentava do homem... (FERNANDES, 1977, p. 142).

Sempre atento a realidade ao seu redor, desde a mais tenra infância, Fernandes questionou suas condições objetivas de vida. Sua visão de sociólogo se deu muito antes do ingresso na universidade, sua humanidade fez com que ele aprendesse, muito antes de ingressar na vida acadêmica, a forma de manifes tação da sociabilidade capitalista no cotidiano de vida dos "de baixo". De um lado, conheceu as possibilidades e abundâncias que a burguesia possuía e de outro, os desafios que são impostos a quem possuí apenas a força de trabalho como meio de subsistência. Estar no âmago dessas contradições possibilitou uma análise sociológica rica e absolutamente crítica da realidade brasileira, como afirmava:

Na casa da minha madrinha Hermínia Bresser de Lima, onde vivi durante uma parte da infância, ou ocasionalmente ia passar alguns dias; e na casa de outros patrões de minha mãe, entrei em contato com o que é ser gente e viver como gente. Além disso, através de várias ocupações, morei 
na casa de empregadores - uma família negra, outra família italiana e parcialmente, uma família sírio-libanesa. Em suma, do "tradicional" ao "moderno", do "nacional" ao estrangeiro, dei-me conta quão grande e complexo era o mundo, e que nada me forçava a encerrar-me no confinamento dos porões, dos cortiços e dos quartos de aluguel em que morava com minha mãe (FERNANDES, 1977, p. 143).

Ao lado da mãe, Fernandes conheceu a dura realidade que está reservada ao filho do/a trabalhador/a. Forçado a morar em barracos e cortiços, nas zonas periféricas, embora vivessem em condição de subsistência, sua mãe sempre o ensinou a ter dignidade e lutar pelo que desejava. Dessa época, Florestan se recordava como sendo uma época que prevalecia a "[...] 'relação de presa' pela qual o homem se alimentava do homem” (FERNANDES, 1977, p. 142) onde apenas os fortes sobreviviam. Ser forte estava além da sua capacidade física em lutar, mas, principalmente, na estratégia de pensar para poder sobreviver aos desafios que a vida impunha, mesmo a uma criança.

Aos 06 anos de idade começou a trabalhar no antigo centro de São Paulo como engraxate. Nesses espaços, o menino percebia atentamente a dinâmica que acontecia ao seu redor, isto é, a forma como os companheiros de mister se relacionava, a questão da luta pelos melhores pontos, como as crianças eram tratadas pelos adultos e que o "pobre" era submetido a um tratamento desumano pela burguesia e pequena burguesia paulistana.

Eu não estava sozinho. Havia a minha mãe. Porém a soma de duas fraquezas não compõe uma força. Éramos varridos pela 'tempestade da vida' e o que nos salvou foi nosso orgulho selvagem, que deitava raízes na concepção agreste do mundo rústico, imperante nas pequenas aldeias do norte de Portugal, onde as pessoas se mediam com o lobo e se defendiam a pau do animal ou do outro ser humano (FERNANDES, 1977, p. 142).

O orgulho "selvagem" que Fernandes se referia foi fundamental para que se forjasse um ser humano íntegro, fiel aos seus princípios e a sua classe de origem. A lealdade foi a grande lição que ele apreendeu nas ruas e deixou como legado em sua obra monumental.

Florestan Fernandes foi forçado pelas circunstâncias da vida a abandonar os estudos aos 09 anos de idade. Sua mãe se preocupava com o fato de que o filho precisava aprender um ofício, tinha receio de que caso ele não aprendesse uma atividade laborativa viria a passar fome depois de adulto. Nesse contexto, ela conhece um alfaiate que se dispõe a treinar Florestan Fernandes. Ele começaria entregando ternos para os clientes ricos da alfaiataria, posteriormente 
passaria a fazer pequenos reparos até que, por ideia da mãe e concessão do patrão, Florestan passaria a viver no trabalho para não gastar dinheiro com passagem e poder extrair o máximo de aprendizado possível ${ }^{2}$. Era a realidade de boa parte da classe trabalhadora que vivia nas ruas durante a semana. Dessa época, Florestan se recorda em entrevistas e relatos biográficos que oscilava entre as duas realidades existentes na sociedade de classes:

O menino que eu era vivia essa amalgamação convertendo-se em um ser humano de tipo especial, fascinado pelo luxo de uns ou pela pompa dos que desciam de carros com motoristas de libré, abrindo as portas, diante do Teatro Municipal ou do Cine Paramount; passando o dia oscilando entre a fome e a fartura trabalhando como se fosse um adulto... (FERNANDES, 1977, p. 145).

Do período que morou naquele serviço, Florestan se recordava de que passou a habitar o porão do estabelecimento, em uma cama improvisada com colchão feito com sobras de tecido, dividindo esse espaço com ratos e baratas e que, na única fresta que dava para a rua, ele via apenas o calçado das pessoas, a sombra que elas faziam na parede, que ele chamaria, posteriormente, do seu "Cine Paramount" particular. De tanto fazer reclamações com a mãe sobre as condições insalubres que ele estava inserido no seu trabalho, um dia, Maria Fernandes decide fazer uma visita ao filho e se depara com a realidade deplorável que ele estava. Imediatamente retirou Florestan de lá e o levou para casa, afirmando que aquele não era um espaço digno "[...] nem para um cachorro" (CERQUEIRA, 2013, p. 23). Sobre essas experiências vividas Fernandes afirma que:

[...] a variedade de ocupações a que precisei dedicar-me ou as aventuras e desventuras que pontilharam a minha infância e uma adolescência tão marcadas pela necessidade de ganhar a vida, de buscar trabalho - por vezes humilhante e degradante - um instrumento de relação com os outros e de pressão sublimadora. Fazendo o que me via forçado a fazer também era compelido a uma constante busca para vencer uma condição em que o lumpen-proletário (e não o operário) definia os limites ou as fronteiras do que não era "gente". Antes de estudar esse processo na pesquisa sobre o negro, vivi-o em todos os matizes e magnitudes. A fronteira que

\footnotetext{
${ }^{2}$ Para maior aprofundamento sobre esse período da vida de Florestan Fernandes, consultar o primeiro capítulo do livro "Florestan Fernandes vida e obra" de Laurez Cerqueira, Expressão Popular, 2013. $2^{a}$ edição, p. 11/30. E também consultar o livro "A Sociologia no Brasil, capítulo 07, Vozes, 1977, volume 7, p. 127-39.
} 
me era negada também era conhecida pela experiência concreta (FERNANDES, 1977, p. 143).

Ainda no que tange as diversas ocupações laborais que exerceu é importante recuperar a época em que trabalhou como garçom no "Bar Bidu", na rua Libero Badaró, no centro antigo de São Paulo. ${ }^{3}$ Esse período foi fundamental para que Fernandes conhecesse pessoas que o incentivaram a retomar os estudos. Como Florestan apreciava muito a leitura, ele sempre estava lendo, entre um atendimento e outro, no referido bar (FERNANDES, 1977, p. 147).

Certa vez, ao ser indagado sobre o que fazia em um canto do balcão sempre que estava sem atender clientes, animado, ele mostra seus livros ao cliente e dizia que aproveitava essas oportunidades de tempo livre para ler. ${ }^{4}$ A partir desse dia, os professores que frequentavam o Bar Bidu passaram a convidar Florestan para debates nos quais ele sempre se destacava pela sua inteligência e percepção de mundo.

Um dia, seus novos amigos questionaram o que ele estava fazendo trabalhando como garçom, ao que Fernandes responde que teve que abandonar cedo os estudos para poder sobreviver e auxiliar na subsistência dele e da mãe. Foi quando os amigos o incentivaram a procurar um curso de madureza ${ }^{5}$.

Animado com a possibilidade de voltar a estudar, Florestan Fernandes chega em sua casa e conta para mãe que decidira fazer o curso de madureza no Colégio Riachuelo, que por ser próximo ao seu local de trabalho facilitaria a permanência na escola. Maria Fernandes se desesperou e disse que não queria que o filho estudasse, ao ser questionada por Florestan o porquê dessa reação, sua mãe diz que tinha medo dele se tornar um homem "das letras" e sentir vergonha dela, por ela não saber ler e escrever. (FERNANDES, 1977)

Fernandes se entristeceu diante da postura da mãe, mas posteriormente formula uma teoria a respeito dessa situação que explica o fato de muitos traba-

\footnotetext{
${ }^{3}$ Quando trabalhou como garçom no Bar Bidu, Florestan Fernandes já estava com 17 anos de idade. Nesse espaço se relacionou com intelectuais de diversas áreas do saber e se destacava pelo seu interesse voraz pela leitura, principalmente seu apreço pelos clássicos da literatura mundial, o que não era comum a um jovem da sua idade vivendo a realidade em que vivia.

${ }^{4}$ Antônio Candido relata que o amigo apreciava a leitura e detestava perder tempo sem fazer nada. Florestan Fernandes lia sempre que tinha oportunidade, fosse nos trabalhos que teve, no estribo do trem, certa vez cruzou com ele pelos corredores da Faculdade Maria Antônia e ele es tava lendo "Uma vida de Buda". Segundo Antônio Candido, o gosto diversificado pela leitura contribuiu para que Fernandes se enriquecesse intelectualmente em todos os aspectos que a leitura pode proporcionar. (Informação extraída do relato de Antônio Cândido no documentário "Florestan Fernandes o mestre", TV Câmara, 2013).

${ }^{5}$ Curso de madureza se assemelha ao antigo supletivo e ao que hoje conhecemos por EJA - Educação para Jovens e Adultos, uma espécie de nivelamento escolar.
} 
lhadores não incentivarem seus companheiros a estudar e buscar atingir patamares sociais mais elevados:

Para mim havia dois tipos de seres humanos e de mundos. Uns viviam dentro do poço e não conseguiam sair dele. Quando tentavam, ou os que andavam na superfície pisavam em suas mãos, e eles caíam, ou os que estavam lá dentro puxavam-nos para baixo. Não havia um sentimento de ódio contra isso: o fato era aceito como "natural", o preço que muitos tinham de pagar por sua sina. De outro lado, contudo, custou-me entender o sentido profundo do comportamento dos que estavam dentro do poço. Somente mais tarde, estudando o negro, é que iria descobrir que não se tratava de demonstração rústica de falta de solidariedade. Era uma forma extrema de amor, de apego humano aos entes queridos. Os que saíam, se separavam, eram perdidos. Aos poucos tornavam-se outras pessoas, mudavam-se de bairro e, por fim, deixavam de visitar os amigos e os parentes ou, mesmo, "rompiam relações" com eles. A alternativa consistia em impedir a evasão, o que criava uma forma inelutável de fraqueza - pois o círculo de ferro se fechava a partir de fora e a partir de dentro - pela qual se consolidava um modo brutal de autodefesa do "nós coletivo" (FERNANDES, 1977, p. 150).

A formulação apresentada por Fernandes explica perfeitamente a dinâmica que perpassa a sociabilidade capitalista, tanto no que diz respeito as classes dominantes não permitirem aos trabalhadores adentrarem seus espaços tidos como privilegiados, se fechando dentro de "círculos de ferro" quase que impenetráveis, quanto o fato da dinâmica apresentada também ocorrer no seio da classe trabalhadora, não significando em absoluto que os companheiros trabalhadores não desejassem que seus iguais saíssem das condições precárias de vida.

Já no curso Madureza, Florestan Fernandes troca de emprego, graças a ajuda de alguns professores, se tornando representante de vendas em uma empresa farmacêutica, com um salário maior e mais tempo para estudar, ele podia se dedicar mais ao curso. Nesse período, Fernandes vai se observando pela primeira vez como intelectual e vislumbra a possibilidade de ser professor (FERNANDES, 1977).

Terminado o curso madureza, decide fazer faculdade. Ele gostaria de ter feito engenharia química, mas o curso era em tempo integral, e as condições concretas não lhe propiciavam as condições financeiras para a aquisição do material didático para a manutenção e a conclusão do curso. Considerando que, em 1941, a USP não oferecia cursos noturnos e ele precisava trabalhar, deveria escolher um curso de meio período. Foi quando optou pelo curso de Ciências 
Sociais da Faculdade de Filosofia Ciências e Letras da Universidade de São Paulo.

A escolha das Ciências Sociais e Políticas ocorreu por conta das oportunidades que coincidiam com meus interesses intelectuais mais profundos. No caso, a "escolha de uma profissão" quase não contou.

Queria ser professor e poderia atingir esse objetivo através de vários cursos. O meu vago socialismo levou-me a pensar que poderia conciliar as duas coisas, a necessidade de ter uma profissão e o anseio reformista de "modificar a sociedade" cuja natureza não conhecia bem, mas me impulsionava na escolha das alternativas. Decidi-me pela seção de Ciências Sociais da Faculdade de Filosofia, Ciências e Letras. Esta herdava um "bicho da cidade", em processo de desdobramento intelectual e da descoberta de si mesmo. Seguindo a ótica atual, alguém poderia escrever: o lumpen-proletariado chega à Universidade de São Paulo. Todavia, não era o lumpen-proletariado que chegava lá; era eu, o filho de uma ex lavadeira, que não diria para a cidade de São Paulo "agora nós", como um célebre personagem de Balzac. Eu levava comigo intenções puras, o ardor de aprender e, quem sabe, de tornar-me um professor de escola secundária (FERNANDES, 1977, p. 154).

Naquela época, para ingressar na faculdade, era necessário passar pelo exame escrito, posteriormente pelo exame oral. Os professores que compunham a banca avaliadora eram estrangeiros, dentre eles, os dois Bastides (intelectuais de grande peso à época). Como não dominava o francês, mas já havia se aproximado de leituras que o ajudariam na realização do teste oral, Florestan solicitou que a sua arguição acontecesse em português. Tendo sido autorizado, ele teve que dialogar sobre a "De la Division du Travail Social" (FERNAN DES, 1977).

O processo de ingresso na universidade não foi fácil, embora ele fosse leitor voraz e tenha se destacado no curso Madureza, existia um déficit na sua formação educacional e cultural, que o colocava em desvantagem comparado aos demais candidatos vindos das grandes elites paulistanas. Entre desistir e tentar dar mais um passo à frente, Fernandes optou por continuar. ${ }^{6}$ Graças ao seu esforço autodidata e interesse pela leitura, consegue ingressar no curso e, em 1941, de 29 candidatos apenas 06 conseguiram uma vaga, dentre eles, Florestan Fernandes.

O ingresso na universidade não significou que as coisas se tornariam "fáceis". A partir daquele momento, Florestan, filho de empregada doméstica,

${ }^{6}$ Mais sobre essa passagem e sobre as demais contidas nesse capítulo consultar o livro: A Sociologia no Brasil, Florestan Fernandes, 1977, cap. 08, p. 140-179. 
autodidata, aluno de um curso Madureza ingressava em um espaço elitista, no qual o professor não se dava ao trabalho de ministrar suas aluas na língua nativa. Antônio Candido, em seu depoimento no documentário "Florestan Fernandes: o mestre" (elaborado pela TV Câmara), diz que os professores tratavam os brasileiros como povo colonizado, quem tivesse interesse em participar dos debates que aprendesse o idioma dos professores. ${ }^{7}$

Frente aos desafios, Florestan Fernandes era consciente do que queria para si. Se dedicou, buscando acesso aos livros de estudos nas bibliotecas públicas da cidade de São Paulo. Por diversas vezes passou a madrugada estudando nesses espaços. Com o passar do tempo foi adquirindo prestígio entre os colegas de classe de aula e professores por sua capacidade ímpar em desenvolver dissertações rigorosas sobre os temas propostos para estudo e pesquisa. (FERNANDES, 1977)

Isso não significa que ele sempre foi assim, como já foi dito, suas lacunas na formação escolar o prejudicaram um pouco, mas ele fazia das críticas o alicerce para subir um novo degrau e da dedicação extrema, o alimento para chegar a ser um intelectual. Sobre esse processo, Fernandes (1977, p. 157) afirma que:

Aquele "não era meu mundo". Eu me descobria e, ao mesmo tempo, sentia crescer dentro de mim uma vocação adormecida, que me dava forças e argúcia para aceitar o desafio de tornar-me um professor e um intelectual... Em suma, o Vicente que eu fora estava finalmente morrendo e nascia em seu lugar, de forma assustadora para mim, o Florestan que eu iria ser.

Por seu brilhantismo acadêmico, Florestan Fernandes passou a despertar interesse em alguns professores, como Paul Hugon ${ }^{8}$, com o qual desenvolveu um trabalho de aproveitamento, estudando o avanço do comércio exterior no Brasil do fim da escravidão a 1940. Com Roger Bastide ${ }^{9}$ fez um trabalho so-

\footnotetext{
7 O documentário intitulado "Florestan Fernandes: o Mestre". Disponível em: < https:// www2.camara.leg.br/camaranoticias/tv/materias/DOCUMENTARIOS/162709-FLORES-

TAN-FERNANDES---O-MESTRE.html >. Sobre a passagem de Florestan Fernandes na universidade e sua dedicação aos estudos, se atentar ao depoimento de Florestan Fernandes Junior.

${ }^{8}$ Paul Hugon foi da cadeira de Economia Política e História das Doutrinas Econômicas da FFCL-USP.

${ }^{9}$ No livro Sociologia no Brasil, no capítulo oito, Florestan Fernandes fala de como precisou se dedicar para mostrar aos professores a sua capacidade enquanto estudante que vislumbrava ser um pesquisador, para isso se dedicava na confecção de trabalhos que despertavam o interesse dos professores, para a partir daí começar a trilhar o caminho que o levou ao patamar de maior soció $\log$.
} 
bre "O folclore em São Paulo". Devido ao seu autodidatismo e origem de classe fez um trabalho excepcional que chamou a atenção do professor. A partir daí passaram a construir um laço de amizade. Graças a Bastide, Florestan conseguiu um trabalho no jornal "Estado de São Paulo" e, posteriormente, no "A folha da Manhã", escrevendo os artigos que lhe interessassem.

Tendo se destacado na graduação, o mestrado e o doutorado foram caminhos inevitáveis para Florestan Fernandes. Com seu rigor científico e dedicação, desenvolveu estudos monumentais, como a sua dissertação de mestrado que discorreu sobre a "Organização Social dos Tupinambás", uma população indígena brasileira que vivia no espaço geográfico que hoje é a cidade de São Paulo e fora totalmente dizimada. O único consenso na academia era o de que era impossível estudar sua organização social por ser uma tribo extinta, mas Florestan Fernandes, aos 27 anos, mostrou ser capaz de desenvolver esse estudo, e, posteriormente, no Doutorado, analisou a "Função da Guerra na Sociedade Tupinambá".

Florestan Fernandes, depois de ter se formado na USP, acaba se tornando professor titular dessa universidade, quando assume a cadeira de Sociologia I, anteriormente ocupada por Roger Bastide, passando a realizar ações que objetivavam romper com o pensamento cultural colonizado, oferecendo status de Ciência à Sociologia brasileira. Mas a ditadura burguesa militar instaurada pelo golpe de 1964 mudou os rumos do projeto de educação e universidade pública que estava sendo elaborado por Florestan e outros intelectuais naquele momento. O governo militar estava decidido a fechar qualquer caminho da universidade pública que estivesse disposto a questionar a ordem burguesa e tivesse como horizonte a "revolução contra essa ordem". Através do Ato Institucional $\mathrm{n}^{\circ}$ 05, o governo militar aposenta compulsoriamente Florestan Fernandes que foi exilado no Canadá, tendo sido o primeiro professor estrangeiro a ser titular de uma cadeira na Universidade de Toronto. Além de ter lecionado no Canadá, Florestan também atuou como docente nos Estados Unidos.

Florestan Fernandes ficou três anos fora do Brasil, lecionando em universidades estrangeiras das quais destaca-se a Universidade de Toronto. Lá, denunciava os crimes do regime burguês militar, analisando a posição que ocupa um país capitalista dependente na ordem mundial neste período, quando decide, enfim, retornar para o Brasil. Ele acreditava que seus estudos contra a ditadura eram mais necessários no Brasil do que no Canadá. Mesmo tendo sido interrogado, preso, exilado, Florestan jamais deixou-se aniquilar: 
Há um Florestan que a ditadura pensou ter morto. Ela não o matou, mas a universidade o perdeu, na medida em que eu repudiei a vida acadêmica e, especialmente, o padrão universitário de trabalho, de vida intelectual e de esperança humana (FERNANDES, 1987, p. 309, apud CERQUEIRA, 2013, p. 105).

Florestan Fernandes sempre dialogou com diversas correntes de esquerda, fossem eles trotskistas, anarquistas, socialistas e comunistas. Desde a década de 1940, quando militou organicamente no PSR (Partido Socialista Revolucionário), para ele não importava a corrente de pensamento da esquerda, mas sim, o horizonte da luta, que era a consolidação de uma nova ordem societária, o Socialismo.

$\mathrm{Na}$ década de 80, do século passado, Florestan recebeu um convite do Partido dos Trabalhadores (PT) para candidatar-se a Deputado Federal, atuando na Assembleia Nacional Constituinte. Os dirigentes do PT à época, acreditavam que a participação de um intelectual do nível de Florestan Fernandes traria muitos ganhos a classe trabalhadora. Sob o slogan: "Contra a Ideia da Força, a Força das Ideias", a campanha de Florestan foi uma das mais belas realizadas até hoje no Brasil. Vieram amigos e admiradores de seus pensamentos, de todas as partes do país, todos formavam aquilo que alguns denominavam de "[...] o incrível exército de Florestan Fernandes" (CERQUEIRA, 2013, p. 116).

Fernandes foi eleito, no ano de 1986, Deputado Federal Constituinte pelo PT, com aproximadamente 50000 (cinquenta mil) votos. O que marcou definitivamente os rumos que a formulação da nova Constituição Brasileira percorreu, pois, Florestan sabia muito bem onde estava "pisando" e os desafios que o aguardavam, mas a única certeza que tinha era que, sendo ele um representante da classe trabalhadora, deveria trazer vitórias para sua classe.

Quando esteve engajado no processo da Assembleia Constituinte, Florestan Fernandes examinou rigorosamente pelo prisma marxista todo o processo, enfrentando embates com diversos adversários políticos e ideológicos e, também, dentro do próprio partido. ${ }^{10}$

\footnotetext{
${ }^{10}$ Após a formação do que seria a bancada constituinte, em reuniões de estratégia e organização do PT, Florestan Fernandes manifestou interesse em participar da subcomissão de educação, vis to que toda sua trajetória acadêmica e de militância estava inclinada na defesa da educação pública gratuita de qualidade. Dentro do partido existiam outros candidatos que se predispunham a assumir a subcomissão pleiteada por Florestan. Mesmo alegando seu histórico de lutas e militância, parece que seu discurso não sensibilizou os colegas de partido, o que o deixou deveras incomoda do, sendo que pensou até em desistir do cargo e retornar para São Paulo. Após uma conversa com Lula, para tentar convencê-lo a não desistir do mandato, Florestan Fernandes permanece como titular da Subcomissão de Educação, Cultura e Esportes. (CERQUEIRA, 2013)
} 
Durante o processo da Assembleia Constituinte, Fernandes representou o PT tanto nas fases da Comissão Temática como na de Sistematização, tendo atuado na Comissão da Família, da Educação, Cultura e Esportes; Ciência e Tecnologia e da Comunicação; foi suplente na subcomissão de Defesa do Estado, da Sociedade e de sua Segurança; na Comissão da Organização Eleitoral, Partidária e Garantia das Instituições. (CERQUEIRA, 2013)

Nas palavras do próprio Fernandes, faltou nos deputados constituintes uma consciência jurídica e política do processo de transformação que a Constituinte representava para o Brasil, mesmo que representasse uma "revolução dentro da ordem" burguesa.

Uma constituição envolve a distribuição do poder na sociedade civil e o modo de usar socialmente o poder político estatal. Se esses são problemas graves nas nações capitalistas mais avançadas, imagine-se na periferia! As constituições anteriores puderam ser protegidas pelos privilégios que a extrema concentração de prestígio social, de riqueza e de poder conferiram às classes dominantes... Agora, não há como estabelecer a "paz social" à força ou obter um mínimo de articulação entre os interesses antagônicos das classes sociais (FERNANDES, 1989, p. 108).

Durante todo o processo Constituinte, Fernandes fez reflexões importantíssimas sobre a realidade que estava inserido. Para analisar a democracia, era preciso entender como se materializa a ordem burguesa e, particularmente, o capitalismo dependente. A "debilidade" da burguesia no Brasil fazia com que a única preocupação com a nova Constituição fosse a de manter o tripé de domínio necessário aos donos do poder, que Florestan formula em sua teoria como sendo a concentração de "prestígio social, riqueza e poder". Em uma sociedade marcada pelo colonialismo, romper com a ordem é ainda mais complexo, e Florestan apontou isso em sua obra e em sua atuação intelectual militante, pois, para ele, o conhecimento somado a militância era a chave mestra que levaria a "revolução contra a ordem burguesa".

\section{FLORESTAN FERNANDES: COERÊNCIA E LEALDADE DE CLASSE ATÉ O FIM}

“As pessoas vão, mas seu amor, suas ideias e seus ensinamentos ficam e é isso que as torna imortais". (FERNANDES JUNIOR, 1995, p. 175, apud CERQUEIRA, 2013, p. 175) 
Era o ano de 1995, Florestan Fernandes Junior havia regressado à sua residência tarde da noite e encontrou um recado de sua mãe dizendo que o pai sofrera uma hemorragia e estava no Hospital dos Servidores Públicos de São Paulo. Quando chega ao hospital, encontra o pai no lado de fora do estabelecimento, vestindo pijama e roupão, exposto ao sereno paulistano. Ao indagar o pai sobre o que ele fazia no final da fila, do lado de fora e não o porquê havia procurado um hospital particular, Florestan responde: fui funcionário público a minha vida inteira e esse é o local que deve cuidar de mim. Segundo relato de Florestan Junior, com muito custo o pai resolveu esperar no lado de dentro do hospital para ser atendido, mas se recusou a passar na frente dos demais que aguardavam atendimento antes dele (JUNIOR, 2004 ${ }^{11}$ ).

A cirrose hepática herdada de um erro médico na década de 1970 havia se agravado e os médicos Silvano Raia e Sérgio Mies convenceram Florestan Fernandes a passar por uma cirurgia de transplante de fígado. Fernandes passa pela cirurgia, mas devido a questões diversas fica em coma na UTI do Hospital das Clínicas. No dia 10 de agosto de 1995, Florestan Fernandes vem a óbito, vítima de outro erro médico, pois segundo os referidos especialistas, Florestan Fernandes não possuía saúde para sofrer uma cirurgia de transplante de fígado, fato que depois de sua morte foi constatado (JUNIOR, 2015 ${ }^{12}$ ).

Florestan Fernandes entra para a história como sendo o pai da sociologia brasileira, mantendo uma coerência entre seus estudos e suas ações até o último instante de sua vida. Suas análises da realidade, embora críticas, eram carregadas de uma esperança capaz de conquistar mentes e corações, fortalecendo a classe trabalhadora nas diversas lutas que enfrentamos, e ainda enfrentaremos, pela consolidação do socialismo.

Quando recorremos a origem de classe do autor apreendemos que a sua formação sociológica não se deu exclusivamente dentro da universidade, mas teve início na mais tenra infância, na qual o olhar atento do "menino Vicente" fez com que as expressões da desigualdade econômico-social existentes na sociedade de classes fossem apreendidas. Isso foi fundamental para que o grande mestre orientasse sua pauta intelectual militante na defesa intransigente dos interesses dos "de baixo", mostrando não apenas a necessidade de um olhar atento a realidade ao seu redor, mas que um verdadeiro intelectual mili-

\footnotetext{
${ }^{11}$ Informação extraída do depoimento de Florestan Fernandes Junior no documentário "Flores tan Fernandes o Mestre", TV Câmara, Brasília, 2004.

${ }^{12}$ FERNANDES JUNIOR, F. O adeus em um olhar: a vida e a morte de Florestan Fernandes. Folha de S. Paulo, sugerido por Antônio David. Disponível em: < https://www.viomundo.com.br/denuncias $/ 137176 . \mathrm{html}>$. Acesso em: 19 maio 2019.
} 
tante jamais deve se deixar cooptar, aniquilar e deve trazer vitórias para sua classe de origem, no seu caso a sua luta incessante era na busca de vitórias para "os condenados do sistema".

No ano em que comemoramos o centenário de Florestan Fernandes, mais do que resgatar a sua memória, devemos buscar apreender as lições deixadas pelo grande mestre no sentido de nos organizarmos enquanto classe trabalhadora na direção de ruptura contra a ordem burguesa, tendo como único horizonte possível a consolidação do socialismo enquanto sociabilidade urgente e necessária.

Por fim, ancorados nas lições apreendidas com o mestre o parafraseamos:

O grande homem não é aquele que se impõe aos outros de cima para baixo, ou através da história; é o homem que estende a mão aos semelhantes e engole a sua própria amargura para compartilhar a sua condição humana com os outros dando se a si próprio, COMO FARIAM OS TUPINAMBÁS!

FLORESTAN FERNANDES, PRESENTE!

\section{REFERÊNCIAS}

CANDIDO, A. Florestan Fernandes. São Paulo: Fundação Perseu Abramo, 2001.

CERQUEIRA, L. Florestan Fernandes vida e obra. 2. ed. São Paulo: Expressão Popular, 2013.

FERNANDES, F. Florestan superou as dificuldades da origem humilde e se tornou um dos intelectuais mais respeitados do País. [Entrevista concedida à] Paulo de Tarso Venceslau. Teoria e Debate. São Paulo: 20 de janeiro de 1991. Edição 13. Disponível em: < https://teoriaedebate.org.br/1991/01/20/ florestan-fernandes/ >. Acesso em: 20 maio 2019.

O desafio educacional. São Paulo: Cortez, 1989.

Brasil: em compasso de espera. São Paulo: Hucitec, 1980. 
A sociologia no Brasil. Petrópolis: Vozes, 1977.

JUNIOR, F. O adeus em um olhar: a vida e a morte de Florestan Fernandes. VIOMUNDO diário da resistência. São Paulo: 28 de outubro de 2015. Disponível em: < https://www.viomundo.com.br/denuncias/137176.html >. Acesso em: 19 maio 2019.

Florestan Fernandes - O mestre. Direção de Roberto Stefanelli. Brasil: TV Câmara, 2004. (34 min.). Disponível em: < https://www.youtube.com/ watch?v=ksAT 6HmEK4 > . Acesso em: 09 mar. 2017. 